\title{
Research on the Related Legal Problems of the Crime of Causing Water Traffic Accident
}

\author{
Zhou Chunxiao \\ WUHAN University of Technology, Wuhan Hubei \\ 1207933201@qq.com \\ Zhou Chunxiao
}

Keywords: the crime of water traffic accident,Criteria for the crime,missing persons,pilot.

\begin{abstract}
The crime of the water traffic accident refers to the traffic accident crime occurred in the coastal waters and the inland waterway navigable waters. Compared with the land traffic accident, the liability subject of the water traffic accident case is more complicated, and the damage caused by the crime is more serious. China's current law on the crime of water traffic accident standards, "missing persons" and "pilot" provisions are not clear, leading to the confusion of judicial practice. According to the characteristics of the water traffic accident, we should establish the standard of conviction, make clear the disappearance of the personnel, and bring the pilot into the main body of the Traffic accident crime.
\end{abstract}

\section{Introduction}

In recent years, with the rapid development of transportation, fishery and fishing industry in China, the quantity and capacity of ships have increased greatly, meanwhile, the water traffic accidents have been increasing, and with the increase of ship tonnage and the increase of freight volume, the casualties and property losses caused by accidents have become more and more serious [1] In reality, however, there are few cases in which the responsible person is held criminally accountable. The causes of this phenomenon are manifold, one of the important reasons is that China's relevant legislation does not have a clear stipulation on the standard of conviction of the crime of water traffic accident. This paper makes a detailed study on the definition of the crime of water traffic accident and the standard of conviction in order to help the relevant legislation and judicature in the future.

\section{Definition of the connotation of the crime of water traffic accident}

The crime of the water traffic accident refers to the traffic accident crime occurring in the coastal waters and the inland waterway navigable waters, in particular, the perpetrator violates the traffic and transportation regulations, causes the serious traffic accident in the water, and causes the serious injury, the death or the public and private property to suffer the heavy loss.

Compared with the land traffic accident, the case of water traffic accident has the following particularity:

First, the subject of responsibility is more complex. From the subject of responsibility, the driver of the road traffic accident is the main responsible person, but the driving process of the ship is very complicated, the normal voyage of the ship needs to be completed by a team, both the crew of the deck and the crew of the engineering department. Any one of the links between the problems can lead to the occurrence of water traffic accidents. At the same time, the main body of ship management has multiplicity, such as ship owners, operators, charterers and so on, they have the obligation to supervise the ship, if the supervision negligence causes the water traffic accident, according to the criminal law supervision negligence theory. (supervision negligence is a new theory of negligent crime in Japanese criminal law Science, Specifically refers to in the dangerous business activity, has the command, the supervisory duty person, to the supervised person's negligent behavior, slack its supervisory duty, causes the harm result to occur, should bear the criminal negligence responsibility.) 
China's current legislation also reflects the supervision of negligence theory, such as the 2000 "Traffic Accident Interpretation," seventh stipulates that unit supervisors, motor vehicle owners or motor vehicle contractors to instruct, force others to violate the law driving caused by serious traffic accidents, the crime of traffic offence conviction penalty, also constitute a traffic accident crime.

Secondly, the damage caused by the crime is more serious. The water environment is complex and changeable, the ship navigation is affected by meteorological and hydrological factors, and the water traffic has a greater risk than land traffic. "Moreover, after the water traffic accident, the ship is in the water environment, cannot rescue people immediately.In the early spring, winter and late autumn season, the drowning crew is very easy to freeze to death because of the low temperature ".[2]

\section{Problems in the crime of water traffic accident in China}

\subsection{The conviction standard of water traffic accident is ambiguous}

China's current criminal law stipulates the crimes of major flight accidents, railway safety operations, and traffic accidents in articles 131,132, and 133, and does not specifically establish the crime of water traffic accidents.In the 2000 "Traffic accident explanation" in the Traffic Accident case registration standard,mainly based on the consideration of road traffic accidents, and does not consider the particularities of water transportation,does not apply completely in the water traffic accident case. "Based on the lack of legislation on the crime of water traffic accident, leading to the maritime administrative organs can not determine whether the water traffic accidents constitute a traffic accident crime,so that the water traffic crime cases of criminal prosecution is really difficult." [3]

\subsection{Legal application of "missing persons" is confusion}

Missing persons, in the civil law, is a legal fact confirmed by legal procedures, named as the declaration of disappearance. When the legal fact is confirmed, it will cause the change of the civil legal relationship, and directly lead to the change of the relationship of right and justice. In criminal law, the consequences of criminal acts on personal injury are disability and death, and there is no "missing person" in any criminal consequence. In other words, in the current criminal law of China, death and serious injury is the consequence that people have to bear the legal result of criminal responsibility, the criminal law does not recognize the disappearance of the person as the consequence of the crime. Therefore, at the request of the principle of legality, it is difficult for the judicial organs to make direct legal judgments on the harmful consequences of disappearance of persons, no matter how many missing persons the perpetrator actually caused, and it is difficult to be linked with criminal responsibility. In fact, in the water environment, it is difficult to get a chance to survive as long as it falls into the waterway. Although the Supreme People's Court in 1992 gave a telephone reply to the Sichuan Provincial High Court for instructions on how to apply the law to the case of water traffic accident, "According to the fact that the defendant's behavior caused the victim's disappearance, he was convicted and punished by traffic accidents.", but until today, The judiciary has not continued to follow the legal norms, the standards for such cases and the scope of sentencing has not been given a clear explanation.

\subsection{The cognizance of pilot's negligent crime is ambiguous}

The pilots refer to the navigation technicians who have their qualification certificates employed in fixed waters to pilot the ships. The main role of the pilot is to assist the master in securing the safe entry and exit of the ship and berthing, and providing technical services for the ship to sail in the port area and to operate from the berthing.

Pilots who provide pilot programmes in a particular area must be familiar with the geographical features, waterways, water depths, currents, navigation marks and local rules and regulations of the 
waters in which they operate and have skilled ship-driving techniques. In practice, pilots with pilot qualification may cause water traffic accidents due to negligence and artificial operation. In this case, should pilots be held legally responsible? At present, the economic loss caused by the negligence or negligence of the pilot is usually borne by the shipowner or carrier, and the pilot only undertakes the corresponding administrative liability or certain civil compensation. However, in case of a traffic accident caused by pilot's failure and suspicion of committing a crime, there is a controversy over the subject of the responsibility of the traffic accidents.

\section{Suggestions on perfecting the crime of water traffic accident}

\subsection{Defining the standard of crime in water traffic accident}

2000 "Traffic accident interpretation" to "death of one person or seriously injured more than three people or can not afford to pay more than 300,000 yuan" as a starting point for the construction of crime, this is different from the death toll and direct economic loss standard set by the Ministry of Transport's "Statistical measures for water traffic accidents", 2002 Statistical measures on water traffic accidents comprehensively consider the harmful consequences of ship tonnage and traffic accidents, and set the major accident standard as "more than 3 deaths or direct economic loss of more than 500,000 yuan". From the above accident grade standards can be seen, water accident grade assessment standard is obviously higher than the land standard, if the road traffic accident loss criteria to measure the water traffic accident, will lead to the face too wide, so that the water transport subject to bear greater crime risk, therefore, 2000 "traffic accident explanation" Can not be fully applied to the crime of water traffic accident, in accordance with the characteristics of water traffic accidents, to establish their own criteria for criminalization, specific reference to the 2002 "Water Traffic Accident Statistics", the water traffic offence conviction standard set as "more than 3 deaths or direct economic loss of more than 500,000 yuan" [4]

\subsection{Accurate definition of "missing persons"}

The determination of death and serious injury caused by traffic accident is of great significance to the establish the crime of traffic accident, but the disappearance of people falling into the water caused by traffic accident has not been evaluated in our present criminal legislation.Long-term legal gaps have led to the practice of the Judicial Department in dealing with the disappearance of persons caused by traffic accidents in different ways, not to prosecute, or to declare death, or to presume death, or to punish directly[5]In the telephone reply of 1992, the case of "whereabouts unknown" in the water traffic accident was stipulated, and the precedent of the conviction and punishment of traffic accident was established.

The telephone reply of 1992 provides a rough plan for the application of law by the judicial organ, although the telephone reply only has the effect of quasi-judicial interpretation, but it effectively solves a big legal problem that has plagued the national wading administrative and judicial authorities to handle the water traffic accident case. The author agrees with this proposition and suggests that the "missing persons" should be included in the crime of traffic accident through judicial interpretation, and the application of this special consequence should be further standardized to provide the legal basis for the judicial organs to punish the victims of water and soil traffic.

\subsection{Defining the standard of entering into punishment for the negligence crime of pilots}

According to the PRC Maritime Code 39th, the master's responsibility for the management of the ship and the driving of the ship shall not be discharged as a result of the pilot's guidance."The People's Republic of China ships crew on duty rules" 46th: The ship is piloted by the pilot, does not lift the master management and driving the ship's responsibility.

As a result, the pilot's offer of pilotage cannot be mistaken for manipulating the ship or directing the ship. The role of the pilot is mainly to provide technical services for the navigation of the ship in 
the port area and the berthing operation. Before the pilot starts to lead, pilots are required to quickly familiarize themselves with the cultural customs, the handling characteristics of the ship, and the status of the ship's navigational equipment by reading the pilot card or consulting the crew, etc. [6] Pilotage is a highly difficult technical work.Pilot must have professional skills, experience in pilotage and perseverance.

Therefore, the programme provided by the pilot is not understood to operate the ship, the provision of pilot programmes has made it truly involved in the work of ship driving, affecting the safety of water transport. The pilot can become the main body of the crime of traffic accident under the condition that Pilot can be the main body of the crime of traffic accident.

\section{References}

[1] Maritime Safety Department of the Ministry of Transport. 2013 China's water traffic safety situation continued to stabilize [J]. China maritime, 2014, (3).

[2] Jiang Xizhen, Yin Xuwei. Basic methods of analysis and investigation on water traffic accidents [J]. Heilongjiang Traffic Science and Technology, 2006, (10).

[3] Jiao Yanpeng. On water traffic accident and its dangerous behavior standard of crime [J]. Jurisprudence, 2012, (9).

[4] Guo Quanbao, on the water traffic Accident crime related legal questions inquiry, Hunan Science and Technology Institute Journal, April 2015 36th Volume fourth period.

[5] Wang Hui. Study on criminal responsibility of water traffic crime [D]. Dalian Maritime University, 2013.

[6] Chen Xuesi: "Pilot, Captain and the Yangtze River Pilotage safety relationship", contained in "China Water Transport" (second half month) 200804. 